\title{
Workshop on Informatics Education: Bridging the University/Industry Gap
}

\author{
J B Thompson and $\mathrm{H} \mathrm{M}$ Edwards \\ School of Computing and and Technology \\ University of Sunderland \\ Sunderland, SR6 0DD, UK \\ barrie.thompson@sunderland.ac.uk helen.edwards@sunderland.ac.uk
}

Summary. The theme for the workshop is "Bridging the University/Industry Gap. It will provide a forum for an examination of the many types of interaction that can occur between universities and industry within the field of informatics (e.g. undergraduate projects with industry, staff exchanges) and the generation of categorizations. It will also allow an opportunity to exchange opinions and views on the key issues that relate to each type of interaction. The overall purpose of the workshop is to provide inputs into the development of a formalised framework that could be used to support not only the documentation of university/industry interactions but also future evaluations of such interactions and the industry practices that they have highlighted.

The workshop represents the third participative input into an international project that is supporting the work of IFIP Working Group 3.4 (Professional and Vocational Education) and which is being funded through the United Kingdom's National Teaching Fellowship Scheme (NTFS). A major aim for the overall NTFS project is to develop guidelines and recommendations regarding the identification of proven industry-related best practices and the incorporation of the treatment of these into both undergraduate and post-graduate computing curricula (including curricula that relate to maintenance of competence for existing professionals).

It is intended that the workshop will have a highly interactive format that will involve the active participation of all attendees. Any formal presentations that are made by the attendees in support of their viewpoints will be relatively short - the emphasis during the day will be in active participation with the goal of producing useful deliverables. Also it is intended that extensive use will be made of activities within small groups which will then report back to the main group. The workshop will close with a "brain storming" session for all participants. This will discuss progress made, identify future goals and strategies, and obtain opinions on current industry best practices that should prove useful within the subsequent stages of the project. 